\title{
Actitudes y expectativas del colectivo de personas con discapacidad hacia la televisión
}

\author{
Expectations and attitudes of people with disabilities towards television
}

\author{
Dr. Francisco Utray \\ Universidad Carlos III de Madrid, Grupo de investigación: TECMERIN. \\ futray@hum.uc3m.es
}

Ddo. Lázaro Echegaray

Universidad del País Vasco (España)

lazaroeche@yahoo.es

Dra. Belén Ruiz

Universidad Carlos III de Madrid

bruiz@inf.uc3m.es

Recibido: 30 de Mayo de 2010 Aceptado: 09 de septiembre de 2010

\begin{abstract}
Resumen
Los medios de comunicación, y más concretamente la televisión, resultan herramientas cruciales para la interpretación y reinterpretación de la realidad social. Sin embargo, no todas las personas acceden de igual manera a los contenidos mediáticos. Es el caso de las personas con discapacidad, que hasta el momento han encontrado importantes barreras en su acceso a los medios de comunicación y más concretamente a la televisión. La implantación generalizada de la televisión digital supone una oportunidad para la incorporación de aplicaciones de accesibilidad que contribuyan a desarrollar el modelo de televisión para todos. En este articulo se presenta un estudio que se ha realizado para analizar la situación actual de los colectivos de personas con discapacidad y sus expectativas hacia la televisión digital como elemento integrador de herramientas generadoras de accesibilidad. Para el caso se ha trabajado con miembros de los colectivos de personas con discapacidad auditiva, visual, física e intelectual, así como con el colectivo de personas mayores. La metodología utilizada ha sido la cualitativa de investigación social, recurriendo a las técnicas de rastreo de fuentes documentales, entrevistas en profundidad y
\end{abstract}


grupos de discusión. Los resultados de la investigación destacan el papel de inclusión e integración social que cumple la televisión y la posible exclusión de los colectivos de personas con discapacidad en el caso de no adoptarse las medidas necesarias para generar participación.

\section{Abstract}

The media, and more specifically, television, are crucial tools for the interpretation and reinterpretation of social reality. However, not everybody has equal access to media contents. This is the case of people with disabilities, who have hitherto encountered major barriers in their access to the media, particularly to television. The introduction of digital television is an opportunity to incorporate accessibility applications and achieve design for all. This article presents a study that has been carried out to analyse the current situation of people with disabilities and their expectations about digital television as an integration element of accessibility tools. To that end, works have been developed with members of the groups of people with hearing, visual, physical and intellectual impairment, as well as with elderly groups. A qualitative methodology of social research has been applied, including documentary sources tracking, in-depth interviews and focus groups. The results of the research highlight the inclusion and integration role of television, as well as the risk of exclusion of the disabled if the necessary measures to generate participation are not taken.

Palabras clave: Discapacidad; accesibilidad; televisión digital; diseño para todos.

Keywords: disability; accessibility; digital television; design for all.

Sumario: 1. Introducción, 2. Método, 2.1 Estrategias metodológicas, 2.2 Población y muestra, 2.3 Servicios de accesibilidad a la televisión digital, 3. Resultados, 3.1 Percepción de los expertos, 3.2 Percepción de los usuarios, 3.3 Transversalidad, 4. Discusión y conclusiones, 5. Referencias bibliográficas. 6 Notas

Summary: 1. Introduction, 2. Method, 2.1 Strategic methodologies, 2.2 Population and sample, 2.3 Digital TV accessibility services, 3. Results, 3.1 Expert assessment, 3.2 Users' perception, 3.3 Transversality, 4. Discussion and conclusions, 5. Bibliographic references.

\section{Introducción}

Una de las misiones de la televisión como servicio público es promover la integración social y satisfacer las necesidades de información y cultura de las personas con discapacidad en busca de su plena participación social (Lledó et al., 2005: 81). La exclusión social, proceso 
por el que un individuo o grupo no se desarrolla de forma integrada en una sociedad respecto a las posibilidades laborales, económicas, políticas y culturales a las que otros sí tienen acceso (Giner et al. 1998), tiene como telón de fondo las crisis y debates sobre el estado de bienestar y genera la denominada modernización excluyente que combina rasgos como la exclusión laboral de aquellos recursos humanos no precisados por los cambios tecnológicos (Barbeito y Vuolo, 1995).

Desde el punto de vista de los efectos sociales de los medios, el final del siglo XX se caracteriza por la influencia profunda de la televisión sobre el conjunto de formas de entender la sociedad (Richeri, 1994). La televisión puede desarrollar el concepto de pertenencia e inclusión actuando como programa de integración al atacar y superar las raíces de los procesos estructurales que generan exclusión (Barbeito y Vuolo, 1995) y otorgando a las personas con discapacidad su derecho a ser ciudadanos integrados socialmente.

Como señala Gutiérrez Gea (2000: 155) no se puede hablar de una televisión de calidad si esta no atiende a las demandas básicas del público sobre información, entretenimiento y ocio. Los colectivos de personas con discapacidad son parte de esos públicos y demandantes de contenidos a los que sólo podrán acceder mediante los servicios de accesibilidad.

Las barreras de acceso que hasta el momento han existido en el medio televisivo y que han afectado a los colectivos de personas con discapacidad y personas mayores, no han permitido la plena inclusión de las mismas en el entramado social al quedar éstas fuera del debate mediático.

La Convención de Naciones Unidas de los Derechos de las Personas con Discapacidadi', en su artículo 9, declara que para alcanzar los objetivos de calidad de vida y la plena igualdad de oportunidades, resulta imprescindible garantizar el acceso de las mismas a los medios audiovisuales. Los estados que han suscrito este texto se han comprometido a asegurar y promover las formas adecuadas de asistencia y apoyo a las personas con discapacidad para asegurar su acceso a los nuevos sistemas y tecnologías de la información, entre los que se encuentra la televisión.

En España desde la aprobación en 2003 de la Ley de igualdad de oportunidades, no discriminación y accesibilidad universal de las personas con discapacidadii (LIONDAU), el ordenamiento jurídico ha ido incorporando el reconocimiento a este derecho en los distintos desarrollos legislativos del sector audiovisual. El Real Patronato sobre Discapacidad publicó 
en 2008 un completo informe sobre las referencias a la accesibilidad a los medios de comunicación audiovisuales en la legislación española y en derecho comparado (Bariffi et al., 2008).

El acceso de todos los ciudadanos a los contenidos mediáticos, evitando cualquier tipo de discriminación que conduzca a situaciones de falta de integración social, es uno de los objetivos que debe perseguir una sociedad que fomenta la igualdad de oportunidades (Alonso 2007). La no adaptación de la televisión en los entornos digitales a las necesidades de estos colectivos está generando barreras de mayor envergadura que las existentes en los sistemas analógicos debido al desconocimiento que implica la novedad de los procesos tecnológicos y que puede generar una total falta de interés por los mismos.

La técnica afecta al mundo social, sicológico y cultural gracias a que modifica los modos de hacer con más eficacia ciertas actividades. La posibilidad de que se aplique, se desarrolle y se adopte, depende de los procesos de institucionalización y de aceptación más o menos crítica de esa institucionalización (Elejalde, 2006: 13).

La implantación de la Televisión Digital supone una oportunidad de ofrecer accesibilidad a los contenidos mediáticos a aquellos colectivos de personas con discapacidad y personas mayores, contribuyendo de esa manera a la definición del concepto de servicio público de la televisión (Utray, 2008: 51).

El objetivo de la investigación que se presenta en este artículo consiste en analizar las actitudes y expectativas de los colectivos de personas con discapacidad y personas mayores ante el proceso de digitalización de la televisión así como el análisis de la situación en la que estos colectivos se encuentran de cara a su relación con los medios audiovisuales.

\section{Método}

\subsection{Estrategias metodológicas}

La investigación realizada para este estudio se ha basado en la metodología cualitativa de investigación social (Valhondo, 2002). Se ha recogido información de primera mano sobre la percepción que los usuarios con discapacidad tienen de la televisión digital. Se incorpora así en el estudio la voz del usuario final, auténtico conocedor de las dificultades a las que se 
enfrentan y de las necesidades especiales que tienen para acceder con normalidad a este medio de comunicación.

La estructura metodológica utilizada se compone de un proceso en tres fases, las cuales quedan directamente relacionadas entre sí al generar cada una de ellas la información necesaria para pasar a la siguiente.

En primer lugar se han analizado las fuentes documentales preexistentes sobre esta materia. Seguidamente se ha procedido a la realización de entrevistas en profundidad con expertos en discapacidad. Por último se han realizado grupos de discusión con usuarios finales con discapacidad.

Los grupos de discusión han resultado un instrumento adecuado para las personas con discapacidad visual y auditiva pero para el colectivo de personas mayores con alto grado de dependencia han sido sustituidos por entrevistas individuales con la colaboración de sus cuidadores. Tampoco se han considerado para los colectivos de personas con discapacidad intelectual, física y mayores en los que se han utilizado los resultados obtenidos en las entrevistas en profundidad con expertos.

\subsection{Población y muestra}

Para la realización de las entrevistas en profundidad se ha recurrido a organizaciones de usuarios y expertos vinculados al movimiento asociativo de la discapacidad.

La representación de las personas con discapacidad visual ha estado a cargo de ONCECIDAT $^{\text {iii }}$ y del RNIB ${ }^{\text {iv }}$ de Reino Unido.

Para el colectivo de personas sordas y con discapacidad auditiva se ha contado con la presencia y participación de la Fundación CNSEv, FIAPAS ${ }^{\mathbf{v i}}$ y Fundación CLAVE ${ }^{\text {vii }}$.

El colectivo de personas con discapacidad física ha estado representado por la $\operatorname{CDFCM}^{\text {viii }}$ y por COCENFE'

Como representantes y expertos en discapacidad intelectual se ha contactado con la asociación FEAPS ${ }^{\mathbf{x}}$ y con el Departamento de Psicología Básica de la Universidad Autónoma de Madrid.

Las personas mayores han estado representadas a través del colectivo Hartu Emanak de Bilbao, la Fundación Vitalia, la Secretaría de Estado de Servicios Sociales, Familia y Discapacidad y el Real Patronato sobre Discapacidad. 


\subsection{Servicios de accesibilidad a la televisión digital}

En España, los servicios de accesibilidad a la televisión están definidos en un reglamento ${ }^{\mathbf{x}}$ que da cumplimiento al mandato de la LIONDAU de desarrollar las condiciones básicas de accesibilidad a la sociedad de la información y los medios de comunicación social. En lo tocante a los contenidos de la televisión, en el artículo $10^{\text {xii }}$ del citado reglamento, se identifican los servicios de subtitulado, audiodescripción e interpretación a lengua de signos. En relación con la televisión digital, el artículo $11^{\text {xiii }}$ establece una relación de las herramientas tecnológicas para garantizar la accesibilidad a los dispositivos de recepción y los contenidos interactivos.

Esta regulación es fruto de un consenso sectorial en el que participaron todos los agentes implicados: administración, usuarios, industria, entidades de normalización e investigadores universitarios (Utray 2008). Por lo tanto se ha considerado una guía válida para el diseño de la investigación.

El subtitulado es un servicio de apoyo a la comunicación que muestra en pantalla, mediante texto y gráficos, la información sonora que se produce en cualquier obra audiovisual. Consiste en la proyección sobre la pantalla de textos escritos que reproducen los mensajes hablados y gráficos asociados a los diversos sonidos, permitiendo a las personas con limitaciones auditivas comprender la información suministrada (Burnham et al., 2008).

Otro servicio necesario para hacer accesible los medios audiovisuales a las personas con discapacidad auditiva es la interpretación a lengua de signos. La lengua de signos es un sistema de comunicación lingüística utilizado tradicionalmente por las personas sordas y sordociegas signantes. Para su utilización en los sistemas audiovisuales se puede incorporar el intérprete en la propia escena o a través de una ventana flotante sobre la pantalla 0 incorporar al intérprete de lengua de signos en la puesta en escena.

La audiodescripción permite a las personas ciegas o con discapacidades visuales acceder a programas de televisión, producciones audiovisuales y otros medios de telecomunicación con imágenes proporcionándoles una descripción narrada de elementos visuales claves que aparecen en ellos. La descripción de elementos tales como acciones, vestuario, gestos y cambios de escena, entre otros, posibilita que una persona ciega o con discapacidad visual siga plenamente la historia. La narración que describe los elementos visuales de la obra audiovisual, realizada por descriptores especializados, se mezcla con su banda sonora aprovechando los huecos que dejan los diálogos (Orero, 2007). 
La interactividad que es un elemento consustancial de los sistemas digitales de la comunicación audiovisual, también tiene que ser accesible. En los equipos de DVD y en televisión digital, los menús interactivos son la primera barrera con la que se encuentra el usuario. Para permitir el acceso de las personas con discapacidad visual a estas pantallas se deben sonorizar los menús mediante un sistema que proporcione al usuario la interpretación verbal automática de los elementos gráficos de la imagen. Este servicio recibe el nombre de audionavegación (Utray, 2008: 159).

La integración de aplicaciones de reconocimiento de voz en los receptores de televisión digital también es necesaria para usuarios con discapacidad física o movilidad reducida, que no pueden manipular el mando a distancia. Se trata de permitir el uso de voz humana como interfaz con una máquina que sea capaz de interpretar la información hablada y actuar en consecuencia.

Por último se debe considerar que es necesario que las aplicaciones y los menús más importantes sean amigables y tengan la opción de personalizarse para adaptarse a las características de cada usuario. La experiencia adquirida en los últimos años para la definición de la accesibilidad a aplicaciones informáticas y a Internet puede ser una base para desarrollar un código de buenas prácticas de ergonomía y usabilidad para la interactividad en Televisión ${ }^{\text {xiv }}$ (Utray et al., 2009: 258).

\section{Resultados}

\subsection{Percepción de los expertos}

Para poder hacer una evaluación sobre las percepciones que tienen los colectivos de personas con discapacidad sobre la accesibilidad a la televisión actual y en concreto a los sistemas de televisión digital terrestre (TDT) se han tratado por separado las valoraciones de los expertos de las de los usuarios finales.

Han sido considerados como expertos los directivos y responsables de las diferentes asociaciones y fundaciones que velan por los derechos de las personas con discapacidad y que en su trayectoria profesional han tratado el tema de la accesibilidad a los medios de comunicación y más concretamente a la televisión. 
En cuanto a su percepción y valoración de la televisión digital y su implantación en el panorama comunicativo español, a pesar de que son conscientes de que traerá mejoras y beneficios para los colectivos a los que representan y ayudas a la integración, se observa en ellos cierto grado de escepticismo. En su opinión, España sufre un retraso en temas de accesibilidad frente a otros países de nuestro entorno y aún queda un largo camino por recorrer para que la implantación de las soluciones de accesibilidad se haga efectiva. También se encuentran preocupados por las consecuencias del cese de las transmisiones analógicas de la red terrestre y los riesgos de exclusión que éste conlleva.

Valoran las mejoras que la televisión digital puede aportar y son conscientes de los beneficios que ofrecerá a los colectivos a los que representan. Las expectativas hacia la televisión digital son superiores a las que tenían en el entorno analógico pues comprenden que ésta es capaz de integrar más y mejores soluciones de accesibilidad que eliminarán, en gran medida, las barreras de acceso que encuentran en la actualidad. Para las personas sin discapacidad la televisión digital significa una nueva oferta de información y entretenimiento. Para las personas con discapacidad, la digitalización de la televisión significa una oportunidad definitiva para poder acceder a todos los contenidos de manera efectiva y sin barreras.

La presencia de servicios de accesibilidad favorece la sensibilización social ante el fenómeno de la diversidad funcional. La televisión puede contribuir a la normalización de la discapacidad. La imagen de la discapacidad ha experimentado un cambio significativo en los últimos años debido a la incorporación en la vida pública de elementos de accesibilidad como las rampas en edificios, los semáforos con sonido o los autobuses urbanos de piso bajo. El ciudadano se hace así consciente de las necesidades del otro y pasa a ser más comprensivo con su situación y con las aplicaciones, tecnológicas y arquitectónicas, que ayudan a mejorar su calidad de vida.

No obstante, sigue existiendo un desconocimiento social sobre la capacidad productiva de esas personas, lo que dificulta su aceptación (Ibáñez y Mudarra, 2008).

La televisión puede convertirse en un elemento integrador de los colectivos con discapacidad en la sociedad al ofrecer información y contenidos que fomentarán el debate y el diálogo social, generando visibilidad de los mismos, identificación y aceptación de las diferencias existentes. La televisión puede ayudar a generar la aceptación social que el colectivo demanda (Goffman, 1963: 19). Por otra parte, activará en los colectivos los mecanismos de identificación y pertenencia que fortalecerán sus lazos intergrupales. Javier Tamarit de la asociación FEAPS, así lo expone en su entrevista: 
"Desde esa perspectiva es necesario construir una televisión para todos, que las personas con necesidades especiales también se puedan beneficiar de ella y que se plantee claramente que la televisión digital es una oportunidad para las personas con discapacidad" (Javier Tamarit, FEAPS).

Existe también la esperanza de que la digitalización de la televisión pueda contribuir a paliar, aunque sea de forma indirecta, problemas como el del analfabetismo que tiene mayor incidencia en los colectivos de personas con discapacidad que en el resto de la población. Esta circunstancia es Especialmente observable en los colectivos de personas sordas y en los de personas con discapacidad cognitiva, usuarios del servicio de subtitulado.

En ambos colectivos existe una limitación importante en cuanto a las capacidades de lectoescritura y el uso del subtitulado puede ser de gran ayuda para favorecer el aprendizaje de la lengua. Esta opinión aparece en distintas entrevistas y concretamente en la realizada a Carmen Jáudenes, directora técnica de FIAPAS:

"En el caso concreto de las personas con discapacidad auditiva, aparecen dificultades de lectura cuando existe una baja competencia en el uso del leguaje oral. La complementación de las dos vías de comunicación, lengua de signos y subtitulado, ayudaría a eliminar esa carencia" (Carmen Jáudenes, FIAPAS).

El colectivo de personas con discapacidad cognitiva puede beneficiarse del subtitulado en combinación con las técnicas de lectura fácil o la integración de elementos icónicos. Tamarit indica que en este colectivo existen competencias lectoras, aunque no muy desarrolladas, cuando los coeficientes intelectuales están entre 50 y 70 . Las personas que tienen mayor grado de discapacidad y menor coeficiente intelectual, no acceden a la comunicación oral ni a la lectura de subtítulos convencionales. En estos casos la metodología de lectura fácil puede ser aplicada para la traducción de textos, tanto en el caso subtitulado como de la audiodescripción.

"La fácil lectura, no es solo fácil lectura, sino fácil comprensión de cualquier elemento del que tú quieras extraer información, es decir, fácil comprensión de iconos, fácil comprensión de textos hablados, fácil comprensión de los botones, por ejemplo: en un mando, en vez de tener números, a lo mejor el propio botón puede ser un icono que también facilitaría las cosas." (Javier Tamarit, FEAPS). 
En relación con el marco regulador de la accesibilidad a la televisión digital se detecta una gran desconfianza. Los expertos consideran que la legislación se limita a una manifestación de voluntades y principios generales pero en la práctica no se cumplen los plazos de aplicación ni se respeta el espíritu de la regulación. Existe una valoración general compartida por los expertos entrevistados en cuanto al incumplimiento de las normas establecidas por la legislación en referencia a la accesibilidad.

El artículo segundo de la LIONDAU define la Accesibilidad Universal como "la condición que deben cumplir los entornos, procesos, bienes, productos, servicios, así como los objetos e instrumentos, herramientas y dispositivos, para ser comprensibles, utilizables y practicables por todas las personas en condiciones de seguridad y comodidad de la forma más autónoma y natural posible". Establece asimismo la obligación de adaptar los medios y dispositivos para el acceso a la comunicación con el fin de que se cumpla la condición de la Accesibilidad Universal.

Los expertos consideran que esta norma no se cumple en el caso de los medios de comunicación o de la televisión ya que los servicios de accesibilidad como el subtitulado o la lengua de signos no están disponibles de forma continuada durante toda la programación. Más grave es la ausencia total de audiodescripción y la inexistencia de cualquiera de las aplicaciones mencionadas para la inclusión de las personas con discapacidad cognitiva. Existen también carencias que surgen por características técnicas de los equipos de recepción que no terminan de adaptarse a las necesidades de los colectivos afectados por la discapacidad.

También argumentan que todavía hay barreras de usabilidad generadas por las dificultades operativas que implica el uso de las tecnologías y que se hacen mayores en las personas con necesidades especiales. Son barreras que tienen que ver con la falta de adaptación de los mandos a distancia o con la complejidad de los menús que éstos despliegan. Se detectan dificultades de acceso a estos menús en relación a la legibilidad de la tipografía y los niveles de contraste entre los textos y su fondo gráfico. Este caso sucede también en el subtitulado.

Estos elementos preocupan a todos los colectivos pero especialmente a las personas mayores, aumentando el problema en aquellas personas que presentan varias deficiencias, caso frecuente en este colectivo. Joan Greening, experta británica en accesibilidad del RNIB, señala la importancia de la innovación en este campo:

"Con cada paso que produce el progreso tecnológico se incrementa el riesgo de que ciertas personas, colectivos o grupos sociales queden al margen y excluidos del uso y acceso a la 
nueva tecnología, hasta el momento en que se encuentra una solución técnica para recuperarlos" (Joan Greening, RNIB).

La Televisión Digital debería encontrar soluciones de accesibilidad capaces de llegar más allá de las necesidades del colectivo al que se dirigen. Algo similar a lo que en su día ocurrió con las medidas destinadas a adaptar el entorno urbano para las personas con discapacidad física o visual y que han sido citadas en párrafos anteriores (rampas, autobuses de piso bajo, etc.). Al final, estas aplicaciones resultaron útiles para toda la sociedad, cumpliendo más funciones que las que se les asignaron en origen y optimizando cada uno de los recursos de acceso. Ese es el camino a seguir para las aplicaciones de accesibilidad a la comunicación audiovisual, la búsqueda de la transversalidad que las haga útiles para la sociedad en general.

Cuando las aplicaciones y elementos de accesibilidad se implantan surge un debate social que genera reconocimiento de la diferencia y aceptación de las necesidades del otro (Goffman, 1963). El momento de aparición de ese debate es un buen punto de partida para generar conciencia social e introducir cambios en las actitudes. La televisión dará cumplimiento a una de las misiones que se le encomiendan como servicio público al promover la integración social y satisfacer las necesidades de información y cultura de las personas con discapacidad en busca de su plena integración social (Lledó et al., 2005: 81).

Los expertos entrevistados también han manifestado su escepticismo sobre la perspectiva de cumplimiento, por parte de las empresas, de las obligaciones que el regulador impone en materia de accesibilidad. La experiencia de lo acontecido en los últimos años conforma esa opinión. Consideran que la industria televisiva no cumple con las medidas establecidas y que tampoco los fabricantes de electrónica de consumo lo hacen.

"Las mejoras en cuanto a accesibilidad llegarán a largo plazo porque a corto plazo existirán resistencias importantes de los propios fabricantes" (Mercedes Belinchon, UAM).

La prestación de servicios de accesibilidad se percibe como escasa y de baja calidad. Esto a pesar de los comunicados de prensa que parten de la industria y de las propias empresas de televisión para publicitar la prestación de servicios de accesibilidad y de la calidad de los mismos. Hasta el momento y en lo relativo a este campo, las empresas parecen no aceptar que en una sociedad competitiva, puedan ayudarse a sí mismas mejorando al mismo tiempo algún aspecto de la sociedad (Arango et al., 2000: 552). 
Según los expertos entrevistados, las aplicaciones básicas como el subtitulado dejan mucho que desear ya que no existe un patrón básico y universal de cómo presentar el servicio. Otras aplicaciones, como la audiodescripción son prácticamente inexistentes en televisión lo que genera el distanciamiento del medio de los colectivos que necesitan este servicio de accesibilidad.

Acusan también una falta de información institucional respecto a lo que es y lo que aporta la televisión digital. Aumenta así el riesgo de exclusión. Es posible que sin información los colectivos no comprendan que la nueva tecnología ofrece mejoras y que queden apartados de ella. Es necesario, declaran, un aumento de la publicidad institucional sobre las ventajas de la televisión digital para evitar la exclusión que la misma implantación puede crear.

\subsection{Percepción de los usuarios}

Como ha quedado reflejado anteriormente, los expertos consideran que existe un incumplimiento de las promesas realizadas acerca de la accesibilidad de la televisión. La percepción de los usuarios coincide con la de los expertos: el colectivo de personas con discapacidad alberga escepticismo y desconfianza hacia la implantación de servicios de accesibilidad en la televisión digital. El acceso a la información les ayuda a minimizar la sensación de exclusión y genera aceptación social. Las dificultades con las que se encuentran para acceder a los contenidos audiovisuales producen inseguridad.

Muestran gran desilusión, incluso molestia, por las carencias de elementos de accesibilidad existente en la televisión. Coinciden con los expertos en la falta de calidad del subtitulado y en la ausencia de audiodescripción. Estas carencias entran en confrontación con los principales criterios asociados a la calidad en televisión, como son la diversidad, la capacidad descriptiva de un programa y la capacidad de representación de la realidad, el punto de vista del espectador, del personal del medio televisivo y del servicio público (Gutierrez Gea, 2000).

Las personas con discapacidad visual denuncian con contundencia la ausencia de sistemas de audionavegación que les permitan acceder a los menús de navegación a través del audio. En los grupos de discusión tuvieron la oportunidad de probar un prototipo de receptor de televisión digital con audionavegación, valorando muy positivamente este tipo de sistemas.

Muestran esperanza hacia el desarrollo tecnológico ya que el mismo implica la capacidad de adaptación de aplicaciones digitales de accesibilidad. Confían en que se desarrollen las funcionalidades de accesibilidad a la televisión que permitan y faciliten su participación. Sus 
demandas y necesidades son completamente legítimas y no perciben la dificultad de integrar soluciones similares a las que ya están disponibles en otros dispositivos como los teléfonos móviles o los equipos informáticos.

Se sienten discriminados por las empresas de televisión y los fabricantes de receptores que, consideran, actúan como obstáculos o frenos a la implantación de elementos de accesibilidad. Se ven a sí mismos como un colectivo poco importante desde el punto de vista mediático, excluidos del marketing televisivo y por tanto con poca fuerza para poder proponer o imponer. Tienen la impresión de que las empresas de televisión no les consideran como público objetivo y necesitan ser vistos como unidades de impacto publicitario para sentirse parte activa del entramado mediático, lo que significaría tener voz y voto en el mismo y representación social.

No se sienten representados por los estamentos políticos y administrativos del estado. Tienen la sensación de que solo se cuenta con ellos para la definición de un marco regulador que en la práctica nunca se cumple. Las declaraciones y textos normativos acaban limitándose a la expresión de intenciones y buenos propósitos que no terminan de hacerse realidad. Manifiestan el deseo de que esas intenciones se lleven a la práctica de forma efectiva. Quieren ver resultados porque los necesitan para mejorar su calidad de vida y su autonomía personal.

Coinciden con los expertos en la falta de información institucional que existe sobre accesibilidad a la televisión. El colectivo experimenta un amplio desconocimiento sobre los aspectos relacionados con el proceso de transito de de la televisión analógica a la TDT. Muchos de ellos manifiestan no saber qué es realmente la televisión digital, ni las posibilidades que ofrece en cuanto a accesibilidad. La falta de información es denunciada incluso por los usuarios de los sistemas más avanzados de televisión digital. Curiosamente, esa información debería llegar desde los medios a los que ellos no pueden acceder al no estar adaptados a sus necesidades. Por tanto tienen el temor de quedar excluidos de la televisión del futuro.

La situación de desinformación, no obstante, no es general; hay usuarios conectados satisfechos y optimistas de cara a un futuro. Estos usuarios sirven como aliciente y ejemplo para el resto del colectivo y hacen que la percepción sobre las nuevas tecnologías de la televisión sea más positiva.

\subsection{Transversalidad}


La transversalidad de las soluciones de accesibilidad hace referencia a la posibilidad de que los servicios y desarrollos técnicos sean útiles y eficaces para otros colectivos además de aquellos para los que han sido creadas. Sirva como ejemplo el caso del mando a distancia que debe servir a todos, incluidas las personas con discapacidad y que por tanto debe ser diseñado y fabricado considerando la diversidad funcional de los usuarios finales. La transversalidad de las aplicaciones de accesibilidad es una demanda que ha surgido tanto en las entrevistas realizadas con los expertos como en los grupos de discusión con usuarios; una demanda que cobra gran importancia en todo el colectivo.

Todas las aplicaciones de accesibilidad son capaces de prestar un importante servicio social más allá del colectivo al que en principio se destinan. Los subtítulos pueden ser útiles para más colectivos que los de personas sordas y con discapacidad auditiva. Adaptados con técnicas de lectura fácil pueden ser utilizados también por personas con problemas de comprensión del entorno, por mayores o incluso por aquellos que llegan a nuestro país desde otros sin conocer el idioma.

La audiodescripción es otra de las aplicaciones que permite transversalidad ya que puede ser útil también al colectivo de personas mayores o las personas con discapacidad intelectual. En el mismo caso se encuentra los sistemas de audionavegación que pueden simplificar el uso de las funcionalidades interactivas para una gran diversidad de usuarios.

La transversalidad de los servicios de accesibilidad resulta especialmente importante para las personas que necesitan de varias aplicaciones para poder acceder a los contenidos televisivos. Es un caso frecuente entre las personas mayores, grandes consumidores de televisión en la actualidad y uno de los que menos informado se encuentra sobre el nuevo panorama televisivo. Según el estudio realizado en el proyecto CALISTO para actualizar los datos sobre horas diarias de visionado de televisión, el $88 \%$ de las personas mayores afirma ver la televisión todos los días y a ese porcentaje debe sumarse el del $5 \%$ que afirman verla "casi todos los días" (Perez-Ugena et al., 2009: 10).

Una idea muy arraigada en los distintos colectivos de usuarios con discapacidad es que el mercado no integra las aplicaciones de accesibilidad por problemas que se relacionan con los fabricantes de los equipos de recepción: la industria no aborda la comercialización de equipos accesibles por considerar que la demanda es muy baja. El colectivo de personas con discapacidad considera que cuanto más alcance tenga cada aplicación, cuantos más problemas sea capaz de solucionar, más impacto de mercado tendrá y por tanto su fabricación será más viable. Con la transversalidad se busca una solución común y efectiva al problema de la accesibilidad desde la idea de que la unión hace la fuerza. Se vuelve sobre 
el concepto tratado con anterioridad de generar aplicaciones globales y extensibles, que generen amplio beneficio social.

\section{Discusión y conclusiones}

Las personas con discapacidad tienen sus esperanzas puestas en que la digitalización de la televisión aportará soluciones de accesibilidad y contribuirá así a su integración social. Sin embargo, se detecta desconfianza con respecto a los plazos de implantación de estos servicios. Los usuarios anhelan que se alcancen los niveles de accesibilidad que ya tienen otros países como Reino Unido o Estados Unidos.

Tienen una actitud reivindicativa con respecto a su derecho de acceso a la información televisiva y manifiestan insatisfacción en relación a los avances que se han producido en los últimos años. La falta de accesibilidad produce en ellos una sensación exclusión e inseguridad.

No se sienten representados convenientemente por las instituciones públicas y consideran que la industria no les tiene en cuenta como clientes objetivos. Reclaman que se les considere consumidores y por lo tanto receptores también de la comunicación comercial. No se ven representados por el marketing social, del que nace el marketing con causa, que trata de desarrollar ejes de comunicación a partir del hecho de compartir una serie de valores con todo el entorno social (Arango et al., 2000: 550). Por otra parte la integración de soluciones de accesibilidad en los dispositivos electrónicos de recepción puede beneficiar a todos los usuarios y no únicamente a las personas con discapacidad.

Tanto expertos como usuarios reivindican el concepto de transversalidad de las soluciones de accesibilidad. Este principio implica que las aplicaciones diseñadas para un colectivo con necesidades especiales pueden ser de interés y ayuda para otras personas, lo que contribuiría a alcanzar las economías de escala necesarias para su comercialización masiva.

En relación con los servicios de accesibilidad se observa una actitud crítica con la calidad del subtitulado o la lengua de signos y una marcada frustración por la carencia de servicios como la audiodescripción o la audionavegación.

El subtitulado se considera insuficiente y se detecta la necesidad de utilizar técnicas de lectura fácil para determinados usuarios con bajas competencias lectoescritoras.

En cuanto a la usabilidad de sistemas interactivos y mandos a distancia se demanda la facilidad de uso y la legibilidad de las interfaces gráficas. 
Las personas con discapacidad y las personas mayores en general se sienten desinformadas sobre el proceso de transición a TDT y sobre las facilidades de accesibilidad que puede aportar. Los expertos solicitan campañas de comunicación especialmente dirigidas a los colectivos con riesgo de exclusión.

La presencia de ayudas técnicas que todo el mundo pueda ver y utilizar si lo necesita, contribuye a la normalización de la discapacidad en la sociedad y a la sensibilización social sobre esta problemática. Contribuye también a generar un debate social sobre la integración de la diversidad. La televisión, entendida como servicio público, puede y debe comprometerse a colaborar con este objetivo permitiendo la participación de todos en la comunicación televisiva sin discriminar a las personas con necesidades especiales.

\section{Referencias bibliográficas}

- Alonso, F. (2007). "Algo más que suprimir barreras: conceptos y argumentos para una accesibilidad universal”. Trans Revista de Traductología. № 11. Málaga: Universidad de Málaga, p. 15-30.

- Arango, H., Casan, R., Chocarro, S., Erba, P., Olarte, L., Ortiz, E. y Saiz, V., (2000): "Marketing Solidario. Los impactos de las tecnologías de la información y de la comunicación en las realidades sociales." Tripodos.com Revista Digital de Comunicació Vol. Extra.

- Barifi, F., Barranco, M., Moreno, L., Palacios, A., Utray, F. y Vida, J. (2008): La accesibilidad universal en los medios audiovisuales de comunicación. Madrid: Real Patronato sobre Discapacidad.

- Barbeito, A.y Vuolo L. (1995): La modernización excluyente. Buenos Aires: Losada.

- Burnham, D., Leigh, G., Noble, W., Jones, C., Tyler, M., Grebennikov, L. y Varley, A. (2008): "Parameters in television captioning for deaf and hard-of-hearing adults: Effects of caption rate versus text reduction on comprehension" Journal of Deaf Studies and Deaf Education № 13 (3) pp 391-404.

- Elejalde, L. (2006): "Tecnología, sociedad y comunicación: Hacia un modelo integrado de los efectos y determinaciones de las tecnologías de la información”. Revista Doxa. Comunicación № 4. 
- Giner, E., Lamo, E y Torres, C. (1998): Diccionario de Sociología. Madrid: Alianza Editorial.

- Goffman, I. (1963): Estigma, la identidad deteriorada. Buenos Aires: Amorrortu.

- Gutiérrez Gea, C. (2000): "Televisión de calidad: Perspectivas de Investigación y Criterios de Evaluación. Demandas básicas del público de información, entretenimiento y ocio". Revista Zer. № 9.

- Ibáñez y Mudarra (2008): Integración Sociolaboral. Trabajadores con discapacidad intelectual en centros especiales de empleo. Madrid: Dykinson.

- Lledó, E, Bustamente, E, Camps, V, Fernández Savater, F y González Urbaneja, F. (2005): "Informe para la reforma de los medios de comunicación de titularidad del Estado". Elaborado por el Consejo creado al efecto, según Real Decreto 744/2004, de 23 de abril. Madrid.

- Richeri, G. (1994): La transición de la televisión. Barcelona: Bosch-comunicación.

- Orero, P. (2007): "La accesibilidad en los medios: una aproximación multidisciplinar". Trans Revista de Traductología. № 11. Málaga: Universidad de Málaga, p. 11-14.

- Pérez-Ugena, A., Salas Martínez A. y Vizcaíno-Larga, R. (2009): "Teleasistencia no invasiva mediante televisión digital: estudio de los hábitos de consumo de televisión de los mayores". Revista Latina de Comunicación Social. № 64.

- Utray, F. (2008): Accesibilidad a la TDT en España para personas con discapacidad sensorial. Tesis doctoral. Universidad Carlos III de Madrid. http://earchivo.uc3m.es//handle/10016/5485

- Utray, F., Pereira, A. y Orero, P. (2009): "The Present and Future of Audio Description and Subtitling for the Deaf and Hard of Hearing in Spain". Meta: Translators' Journal Vol. 54, n⒉ Montréal: Les Presses de l'Université de Montréal.

- Valhondo, D. (2002): Gestión del Conocimiento. Madrid: Díaz de Santos.

\section{AUTORÍA:}

Esta investigación se ha realizado con la colaboración del Centro Español de Subtitulado y Audiodescripción, de la Universidad Carlos III de Madrid y del proyecto de investigación 
ACANTO, financiado por el programa AVANZA del Ministerio de Industria, Comercio y Turismo.

Francisco Utray Delgado es licenciado Ciencias de la Información por la Universidad Complutense de Madrid y Doctor por la Universidad Carlos III de Madrid en donde ejerce como Profesor Asociado en el Departamento de Periodismo y Comunicación Audiovisual. Es también Coordinador Técnico del Centro Español de Subtitulado y Audiodescripción (CESYA) dependiente del Real Patronato sobre Discapacidad. En los últimos años ha participado en diversos proyectos de investigación relacionados con la accesibilidad a los medios audiovisuales para personas con discapacidad.

Datos de contacto:

Francisco Utray Delgado

Universidad Carlos III de Madrid

Centro Español de Subtitulado y Audiodescripción

Avenida de Gregorio Peces-Barba, 1

28918 , Leganés - Madrid

916244029 / 690877605

futray@hum.uc3m.es

Lázaro Echegaray es licenciado en Ciencias Políticas y Sociología por la Universidad de Granada y doctorando en periodismo en la Universidad del País Vasco (UPV). En la actualidad da clases de Investigación de Mercados en la Escuela Universitaria de la Cámara de Comercio de Bilbao (EUCCB) y trabaja como investigador social y de mercados. Ha colaborado con el Centro Español de Subtitulado y Audiodescripción en numerosos proyectos relacionados con la accesibilidad a los medios audiovisuales para personas con discapacidad.

Belén Ruiz Mezcua es licenciada en Físicas por la Universidad Complutense de Madrid y doctorada en Físicas por la Universidad Politécnica de Madrid. En la actualidad es profesora titular del Departamento de Informática de la Universidad Carlos III de Madrid y es la directora técnica del Centro Español de Subtitulado y Audiodescripción (CESYA) 

desarrollo tecnológico y promoción de la innovación Pedro Juan de Lastanosa, siendo responsable del laboratorio sobre discapacidad. Es miembro del Centro de Innovación Tecnológica de Discapacidad y personas mayores y ha dirigido un curso de tecnologías de apoyo para personas con dependencia en la UC3M.

\begin{abstract}
i [1] La Convención sobre los Derechos de las Personas con Discapacidad es un tratado internacional que protege los derechos de las personas con discapacidad. La Asamblea General de las Naciones Unidas aprobó la Convención el 13 de diciembre de 2006. El documento ha sido firmado por 82 países, y en España el texto entraba en vigor en mayo de 2008 (Instrumento de Ratificación de la Convención sobre los derechos de las personas con discapacidad. Boletín Oficial del Estado 2008, núm. 96).
\end{abstract}

ii [2] Ley 51/2003, de 2 de diciembre, de Igualdad de Oportunidades, no Discriminación y Accesibilidad Universal de las Personas con Discapacidad (LIONDAU) establece un marco básico para el desarrollo de la accesibilidad y define el concepto de 'transversalidad de las políticas en materia de discapacidad', principio en virtud del cual las necesidades y demandas de las personas con discapacidad se han de tener en cuenta en cualquier desarrollo normativo posterior (Véase Boletín Oficial del Estado 2003, núm. 289).

iii [3] CIDAT, Centro de Investigación, Desarrollo y Aplicación Tiflotécnica, es el área de la ONCE, Organización Nacional de Ciegos Españoles, cuyo objetivo es procurar a sus afiliados los medios técnicos necesarios para su desarrollo global laboral y educativo y su plena integración social.

iv [4] RNIB, Royal Nacional Institut for Blind People, es la organización de representación de las personas con discapacidad visual del Reino Unido.

v [5] Fundación CNSE inició su actividad en el movimiento asociativo de las personas sordas en 1936 con el fin de representar sus intereses. Entre sus fines destacan la Supresión de Barreras de Comunicación y el Acceso a las Nuevas Tecnologías, entre otros, como objetivos para la mejora de la calidad de vida de las personas sordas

vi [6] FIAPAS, Confederación Española de Familias de Personas Sordas, es una asociación que surge en 1978 para dar respuesta a las necesidades que se plantean las familias de discapacitados auditivos y a los propios afectados. Trabaja para garantizar al colectivo de personas con discapacidad auditiva el acceso a la comunicación, la información y al conocimiento que toda persona necesita para el desarrollo personal.

vii [7] Fundación CLAVE Caring for Hearing Impairment es una entidad benéfica británica cuya delegación en España tiene como principal objetivo actuar sobre las disciplinas que inciden en el desarrollo integral de las personas con deficiencia auditiva y su entorno, para mejorar sus condiciones de vida.

viii [8] CDFCM, Coordinadora de Disminuidos Físicos de la Comunidad Madrileña.

ix [9] COCENFE, Confederación Española de Personas con Discapacidad Física y Orgánica

x [10] FEAPS, Confederación Española de Organizaciones a favor de las personas con discapacidad intelectual

xi [11] REAL DECRETO 1494/2007, de 12 de noviembre, por el que se aprueba el Reglamento sobre las condiciones básicas para el acceso de las personas con discapacidad a las tecnologías, productos y servicios relacionados con la sociedad de la información y medios de comunicación social (véase Boletín Oficial del Estado 2007, núm. 279).

xii [12] Artículo 10: "Condiciones básicas de accesibilidad a los contenidos de la televisión. 1. Las personas con discapacidad tendrán acceso a los contenidos de los medios de comunicación audiovisual, con arreglo a las disponibilidades que permite

Facultad de Ciencias de la Información - Universidad de La Laguna

Avenida César Manrique, s/n; Campus de Guajara

38071 La Laguna, Tenerife (Islas Canarias - España)

www.revistapangea.org | Pág. 72 
el progreso técnico, los diseños universales y los ajustes razonables que, para atender las singularidades que presentan estas personas, sea preciso llevar a cabo. 2. Los contenidos audiovisuales de la televisión serán accesibles a las personas con discapacidad mediante la incorporación de la subtitulación, la audiodescripción y la interpretación en lengua de signos, en los términos establecidos específicamente en la legislación general audiovisual, que regulará, con carácter de norma básica, las condiciones de acceso y no discriminación en los contenidos de la televisión".

xiii [13] Artículo 11: "Condiciones básicas de accesibilidad a la televisión digital. 1. Las administraciones públicas adoptarán las medidas necesarias para garantizar el acceso de las personas con discapacidad a los servicios de televisión digital, de acuerdo con los principios de accesibilidad universal y diseño para todas las personas. 2. Las administraciones públicas adoptarán las medidas necesarias para garantizar a las personas con discapacidad la existencia de una oferta suficiente de equipos receptores de televisión digital que permitan recibir sus contenidos, faciliten la navegación a través de los menús de configuración, las guías electrónicas de programación, los servicios interactivos y otros contenidos textuales, así como todas las prestaciones básicas que ofrecen los receptores de televisión digital, de acuerdo con los principios de accesibilidad universal y de diseño para todos. Las herramientas de accesibilidad, que a tal efecto se utilicen, podrán integrar los siguientes elementos tecnológicos: a) Conversión de texto a voz para favorecer la navegabilidad de los menús de configuración, las guías electrónicas de programación y los servicios interactivos y otros contenidos textuales. b) Aplicaciones de reconocimiento de voz para efectuar operaciones de configuración, de solicitud de información de las guías electrónicas de programación o empleo de servicios interactivos u otros contenidos textuales. c) Ergonomía en los receptores de televisión digital, así como en todos sus dispositivos asociados, y, muy especialmente, en el diseño de los mandos a distancia. d) Aplicaciones de personalización para que, personas con discapacidad puedan configurar los receptores de televisión digital, y, muy particularmente, los parámetros de visualización: tamaño y color de la fuente de letras, color de fondo, contraste y otros. e) Otras herramientas técnicas diseñadas para hacer accesibles los contenidos recibidos a través de la televisión digital a las personas con discapacidad, facilitando el manejo del receptor y permitiendo una recepción de la televisión digital sin barreras y adecuada al tipo y grado de discapacidad. Las administraciones públicas, en la esfera de sus respectivas competencias, fomentarán la difusión pública de las medidas de accesibilidad a la televisión digital, coordinarán actuaciones y sinergias entre todos los agentes implicados, y desarrollarán planes de investigación, desarrollo e innovación (l+D+i), a fin de favorecer la implantación y la puesta en práctica de las tecnologías necesarias para que las personas con discapacidad tengan pleno acceso a la televisión digital. Igualmente, las administraciones públicas implicadas, promoverán el desarrollo de políticas de normalización, códigos de buenas prácticas y herramientas que incorporen requisitos de accesibilidad".

xiv [14] Véase la norma UNE 139.803 "Aplicaciones informáticas para personas con discapacidad. Requisitos de accesibilidad para contenidos en la Web" y las recomendaciones del consorcio W3C sobre accesibilidad al WEB (WAI- Web Accessibility Initiative)

\section{Forma de citar este artículo en bibliografías}

Utray, Echegaray y Ruiz (2010): "Actitudes y expectativas del colectivo de personas con discapacidad hacia la televisión”, en Revista PANGEA, 1, páginas 54 a 73. Red Académica Iberoamericana de Comunicación. Recuperado el __ de __ de 2 ___ de: http://revistapangea.org/2010/09/13/01-01-103/ 